\title{
ON THE SIGNIFICANCE AND UTILIZATION OF SECONDARY MAGNETIZATIONS IN RED BEDS *1
}

\author{
ROB VAN DER VOO ${ }^{* 1, \star 2}$, STEVEN G. HENRY *2 and HENRY N. POLLACK *2 \\ *1 Lamont-Doherty Geological Observatory, Palisades, N.Y. 10964 (U.S.A.) \\ *2 Department of Geology and Mineralogy, University of Michigan, Ann Arbor, Mich. 48109 (U.S.A.)
}

(Received January 20, 1977; revised and accepted April 12, 1977)

\begin{abstract}
Van der Voo, R., Henry, S.G. and Pollack, H.N., 1978. On the significance and utilization of secondary magnetizations in red beds. Phys. Earth Planet. Inter., 16: 12-19.

We document three cases of observed Quaternary or much older secondary magnetizations in red beds. A better than usual knowledge about past and present temperature conditions enables us to compare these secondary magnetizations with theoretical relationships between relaxation time and the temperature of acquisition of viscous partial thermo remanent magnetizations (VpTRM's). Arguments can be made for a viscous-thermal origin of the secondary magnetizations in two of the red bed collections, involving Beltian argillites from Montana and Late Precambrian red beds from the Michigan basin. In the third case, involving Upper Keweenawan sediments from the Upper Peninsula of Michigan, a chemical origin must be assigned to the secondary magnetizations, because thermal and viscous causes can be ruled out. Stability, blocking-temperature ranges, and discreteness of secondary and characteristic magnetizations are very similar for all three of the red bed collections, so that apparently no magnetic criteria exist to distinguish between partial remagnetizations of thermal or chemical origin in red beds. However, when thermal causes can be documented the theory of VpTRM acquisition offers possibilities for palaeo-heat-flow determinations.
\end{abstract}

\section{Introduction}

It has long been realized that natural remanent magnetizations (NRM's) usually consist of superimposed vectorial components of magnetization. Demagnetization techniques employing alternating fields, temperature, or chemical leaching can elucidate this multivectorial nature of NRM, provided that the spectra of coercivities, blocking temperatures, or solubilities of the mineral grains carrying the various magnetic components are discrete (i.e., they do not overlap much). In turn, any spectral discreteness may depend on the mode of acquisition of each magnetic component: common modes of secondary acquisition include chemical, thermal, or viscous origins, or any combina-

\footnotetext{
^1 Lamont-Doherty Geological Observatory Contribution No. 2590.

$\star 2$ Permanently at Department of Geology and Mineralogy, University of Michigan, Ann Arbor, Mich. 48109, U.S.A.
}

tion of these three, such as viscous partial thermoremanent magnetizations (VpTRM's).

Most frequently secondary magnetizations have been considered to be of recent origin, i.e., they have been thought to be carried by that fraction of the magnetic minerals which have inherent low stability. This only applies when the magnetic or thermal relaxation times or the chemical stabilities of the minerals are geologically speaking so low that the original magnetization (or a fraction thereof) is re-aligned in subsequent fields. Repeated re-alignment then results in directions of secondary magnetization close to the present-day local geomagnetic field direction.

The observations of secondary magnetizations, which however are not of recent origin, can therefore in theory be interpreted as indicative of some specific (thermal, chemical, magnetic) event. Such secondary magnetizations can be of considerable interest and in this paper we will discuss some specific examples in red beds. 
Before describing these examples, however, it may be useful to establish some qualifying as well as quantifying criteria. Previously, any secondary magnetization was considered to be "noise", and satisfactory analysis of NRM was only completed when this noise (hopefully) had been eliminated. Now, more attention is being paid to the nature of non-recent secondary magnetizations and a number of techniques have recently been proposed to document and determine the directions of such components: great circles of remagnetization in equal-area projections (Halls, 1976); least-squares mathematical modelling of decay curves (Stupavsky and Symons, 1976; Williamson and Robertson, 1976); or vector subtraction (Zijderveld, 1967, 1975; Roy and Park, 1974; Buchan and Dunlop, 1976, fig. 8). Granted the basic assumptions about degrees of spectra discreteness, lack of random noise, etc., all these methods work satisfactorily for the actual analysis. However, if one wants to visualize and document the existence of a given vectorial component of magnetization, and thereby provide the reader with a convincing case, the Zijderveld method is most useful. Therefore, we will make use of orthogonally projected diagrams to illustrate the demagnetizations and our vector analysis in this paper.

\section{Interpretation of secondary components}

Once the directions of secondary magnetizations are determined, their interpretation must rely on theoretical or empirical knowledge about possible modes of acquisition. Except for secondary magnetizations of thermal origin (pTRM or VpTRM), little quantifying work has been done. For example, the conditions for partial chemical remagnetization are poorly understood and they are not easily distinguished from other types of magnetization. For VpTRM, however, some theoretical studies have recently been made to relate relaxation time to blocking temperatures for magnetite and hematites (Pullaiah et al., 1975; Schmidt, 1976). The graph of Fig. 1a, for instance, illustrates that for hematite a VpTRM acquired at $150^{\circ} \mathrm{C}$ over $10 \mathrm{~m} . \mathrm{y}$. will only be fully eliminated at $400^{\circ} \mathrm{C}$ in a laboratory experiment of $1 \mathrm{~h}$ duration. This type of truly "viscous" acquisition Dunlop and Buchan (Pullaiah et al., 1975) labeled B-type; at higher temperatures, close to the Néel temperature, there is much less divergence between long-range acquisition temperatures and short-range laboratory temperatures (A-type).

Because of a better than usual knowledge about the history of the rocks involved, the cases of observed secondary magnetizations that we will discuss here may be useful for empirical calibration of the graph of Fig. 1a. All three cases involve red beds with the magnetic carrier being almost exclusively hematite. Two of the red bed collections, one from ca. 1.3 b.y. B.P. argillites in Montana, and the other from ca. 1.000 m.y. B.P. buried red sandstone in the Michigan basin, displayed secondary magnetizations which can be fairly well documented to be of thermo-viscous
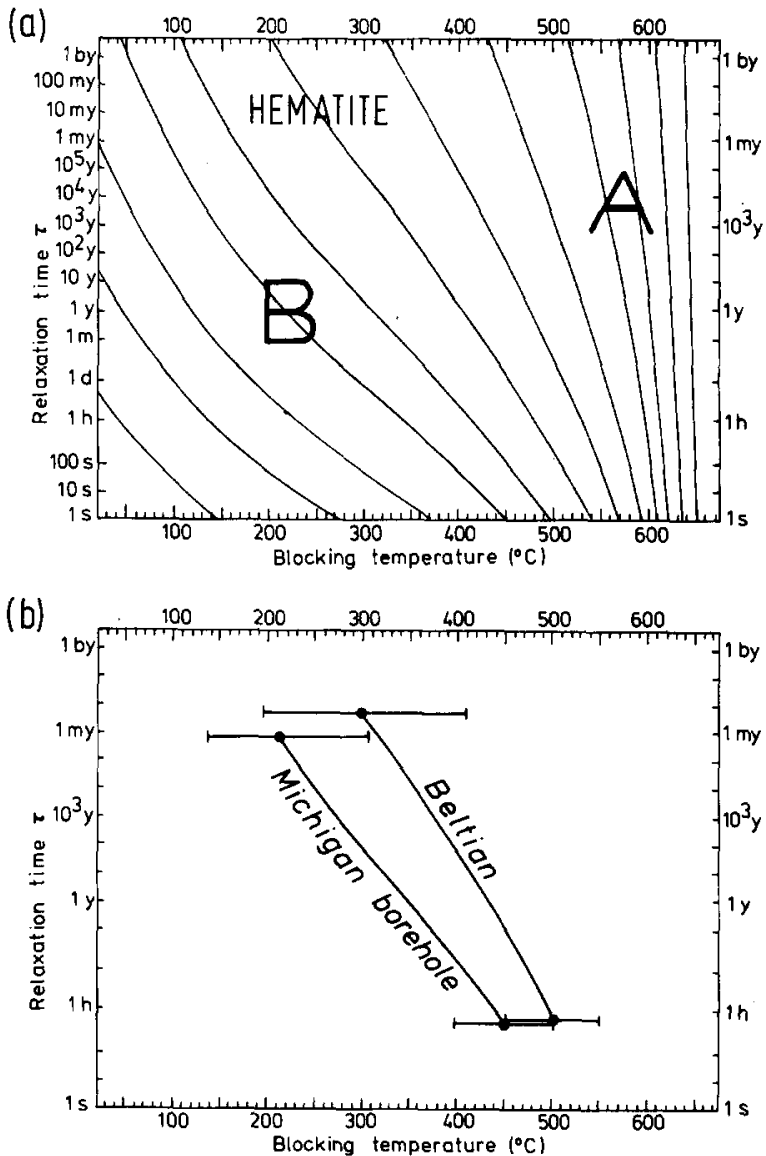

Fig. 1. A. Blocking-temperature curve for hematite, as calculated by Dunlop and Buchan (in: Pullaiah et al., 1975). B. Two cases of probable VpTRM plotted in Dunlop and Buchan's diagram (see text). 
origin, though the possibility of chemical changes in the Montana argillites affecting the hematite cannot be fully excluded. On the other hand, the secondary magnetization in ca. 1.0 b.y. B.P. red beds and dark shales from the Upper Peninsula of Michigan must be of chemical origin, since viscous and thermal effects can be ruled out. Fig. 2 shows the locations of these red bed collections.

\section{Secondary magnetizations in the buried red beds of the Michigan basin}

In 1975, a $5.3 \mathrm{~km}$ deep borehole was drilled near Ithaca, Michigan (Fig. 2). Palaeomagnetic samples obtained from this drillhole were from a mafic igneous rock at $5.3 \mathrm{~km}$, and from Precambrian red sandstones, siltstones, and shales at three different depths, 4.08 , 4.09 and $4.59 \mathrm{~km}$. The characteristic magnetizations of the fully oriented igneous samples yielded a Late Precambrian-Cambrian (?) pole position at $9.0^{\circ} \mathrm{S}$, $158.0^{\circ} \mathrm{E}$. The three red bed samples were not oriented, but their azimuthal orientations could be inferred from the directions of the secondary magnetizations; their directions are steeply down (as was the case with the igneous samples) and have been assumed to have northerly declinations, close to the present-day geomagnetic field direction (Watts and Van der Voo, 1976). With these inferred orientations, the characteristic magnetizations of the red beds yielded a Late Keweenawan pole (ca. 1.0 b.y. B.P.) at $7^{\circ} \mathrm{N}, 174^{\circ} \mathrm{E}$. Temperatures measured in situ at the burial depths ranged between 110 and $130^{\circ} \mathrm{C}$, which is the normal temperature range for these depths; these elevated

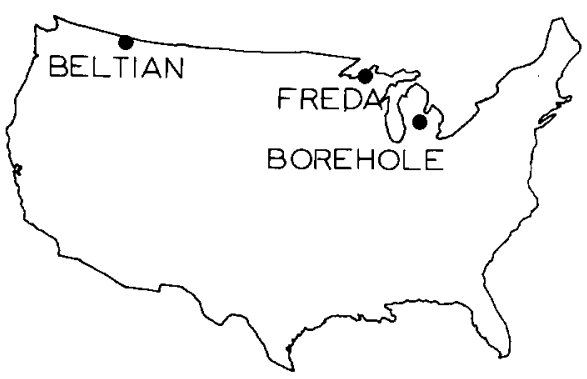

Fig. 2. Index map of the U.S.A. showing the sampling localities for the red bed collections mentioned in the text. temperatures can be held responsible for the large secondary magnetizations present in the igneous and red bed samples. In Fig. 3 demagnetization diagrams are shown of the red bed samples, and it can be seen that the secondary magnetizations are eliminated between 20 and $\sim 500^{\circ} \mathrm{C}$. We have plotted the observed maximum blocking temperatures of $400-500^{\circ} \mathrm{C}$ in Dunlop and Buchan's theoretical graph. The predicted VpTRM acquisition is illustrated by the curve labeled "Michigan borehole" in Fig. 1b; in view of the normal polarity (directed steeply down) of the secondary magnetizations, we estimate that the maximum time for the acquisition of a VpTRM with a recent field direction must have been about 0.7 m.y. B.P., i.e., the duration of the last normal polarity epoch (Brunhes). The temperature range of VpTRM acquisition that can be deduced from Fig. $1 \mathrm{~b}$ is between 130 and $300^{\circ} \mathrm{C}$, somewhat higher than the present burial temperatures of the rocks. This disagreement may result from minor chemical changes or a greater burial depth during Pleistocene ice loading; it could also be attributed to the presence of $\mathrm{Ti}$ in the hematites or to grain sizes of the hematites different from those used for the construction of the theoretical graph.

\section{Secondary magnetizations in the Beltian Spokane Formation, Montana}

A thick miogeosynclinal sequence of Beltian sediments is exposed in Glacier National Park, Montana. The red argillites of the Spokane Formation form part of this sequence and they were investigated palaeomagnetically by Vitorello and Van der Voo (1977). The results will be briefly summarized here. Above temperatures of $600-650^{\circ} \mathrm{C}$ magnetizations were found with directions similar for all samples: the characteristic directions. Demagnetization diagrams are shown in Fig. 4, displaying these high-temperature components. Further directional information is shown in Fig. 5. The pole position calculated from the hightemperature directions agrees well with other results of Helikian age (ca. 1.3 b.y. B.P.). It was further observed that in some samples demagnetization removed not only a soft viscous remanent magnetization (VRM) of recent origin, but also an intermediate component, with a direction clearly divergent from the presentday field direction, as well as from the characteristic 


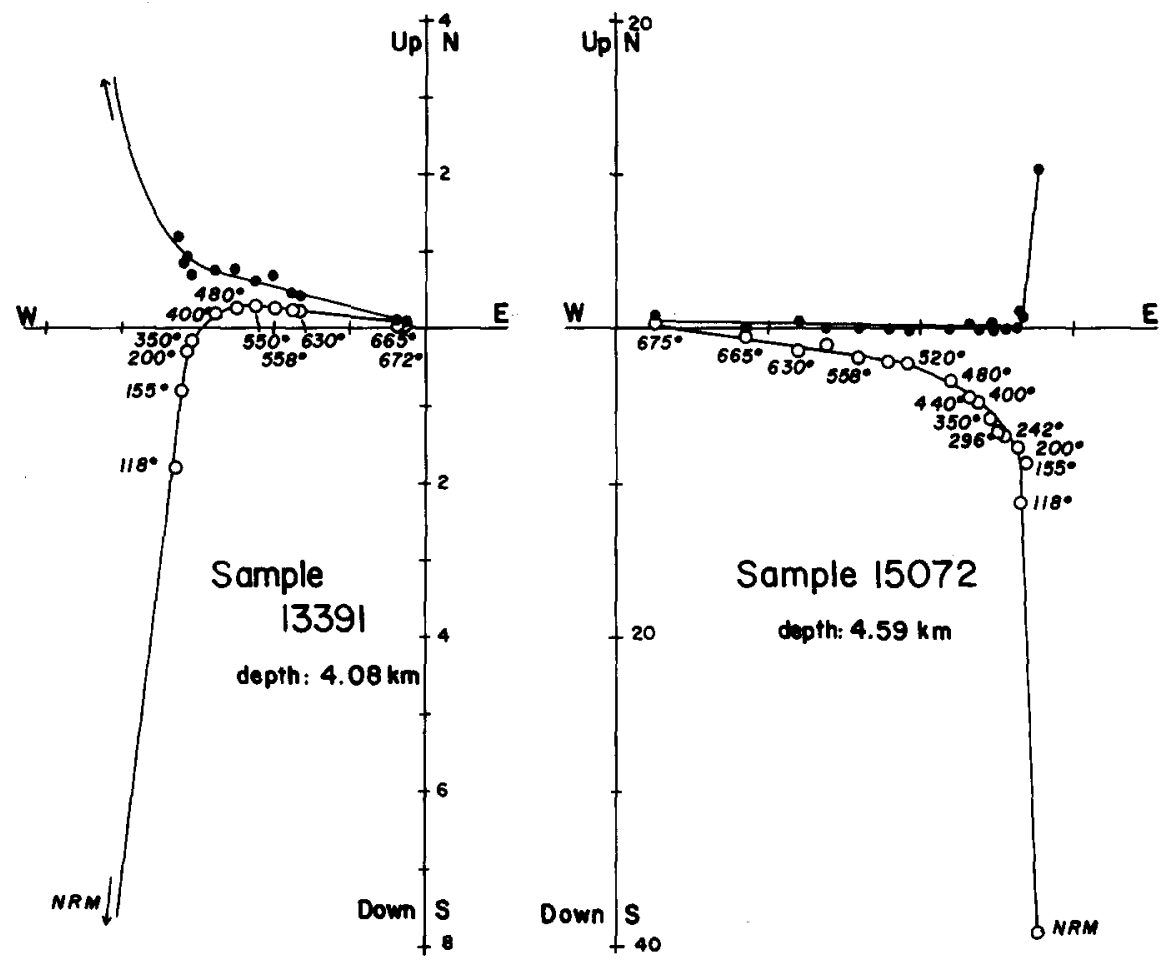

Fig. 3. Orthogonal projections of the successive end-points of the magnetization vector during progressive thermal demagnetization. Solid symbols represent projections on the horizontal plane, open symbols on the E-W vertical plane. Samples illustrated are from the buried Precambrian red beds of the Michigan basin. Note the strong secondary magnetizations, directed steeply down; units on either axis in $10^{-3} \mathrm{~A} \mathrm{~m}^{-1}\left(10^{-6}\right.$ e.m.u. $\left.\mathrm{cm}^{-3}\right)$. Above temperatures of about $480^{\circ} \mathrm{C}$, the characteristic magnetizations are revealed, with directions similar to those of the Upper Keweenawan sediments shown in Figs. 7 and 8 (taking into account the reversed polarity of sample 15072 ).

directions (Fig. 4d, Fig. 6a). These intermediate directions are plotted in Fig. 6b. A comparison of the pole position calculated from the intermediate directions (at $5^{\circ} \mathrm{N}, 163.5^{\circ} \mathrm{E}$ ) with the North American apparent polar wander path, suggests an EocambrianCambrian age for this magnetization.

Intrigued by the implications of this partial remagnetization and its age for the geological history of the sediments, we searched in the literature and found support for a marked thermal event during the latest Precambrian in this area in several publications. Apparently, the red beds of the Spokane Formation underwent a high-temperature diagenesis or low-temperature metamorphism in the latest Precambrian, since illite produced by this event has been dated by Goldich et al. (1959) as circa 0.75 b.y. old. Eslinger and Savin (1973), moreover, have estimated from ${ }^{18} \mathrm{O} /{ }^{16} \mathrm{O}$ ratios of coexisting quartz and illite, that the tempera- tures responsible for the low-temperature metamorphism ranged up to $300^{\circ} \mathrm{C}$. Stewart (1972) postulated that during this time the area was situated near a newly-formed continental rift system; using presentday rifts as a model, enhanced heat flow and elevated burial temperatures are plausible effects and may have caused the partial remagnetization. It must be noted that removal of the overburden above the Spokane Formation did not occur until relatively late in Phanae rozoic time (Ross, 1959). This evidence does not support the idea that our typical Eocambrian-Cambrian magnetic directions resulted from cooling through uplift and erosion.

Although a thermal cause can thus be documented, it may be possible that chemical changes have accompanied the event. Whether these chemical changes in. volved the magnetic minerals depends on the initial mineral assemblage and their relative stabilities. At 

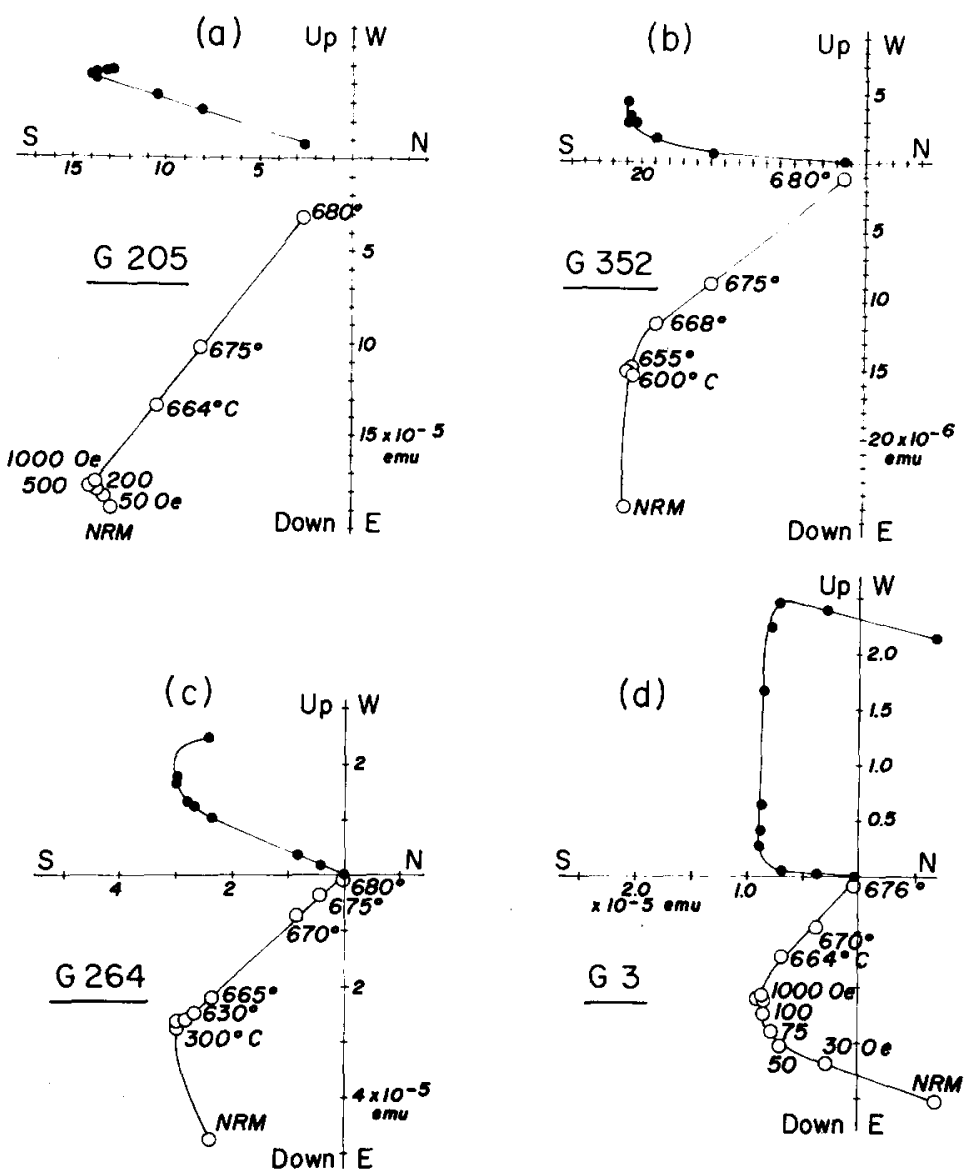

Fig. 4. Orthogonally projected demagnetization diagrams (as in Fig. 3) of samples from the Beltian Spokane Formation (from Vitorello and Van der Voo, 1977). The sample in (d) shows three components of magnetization.

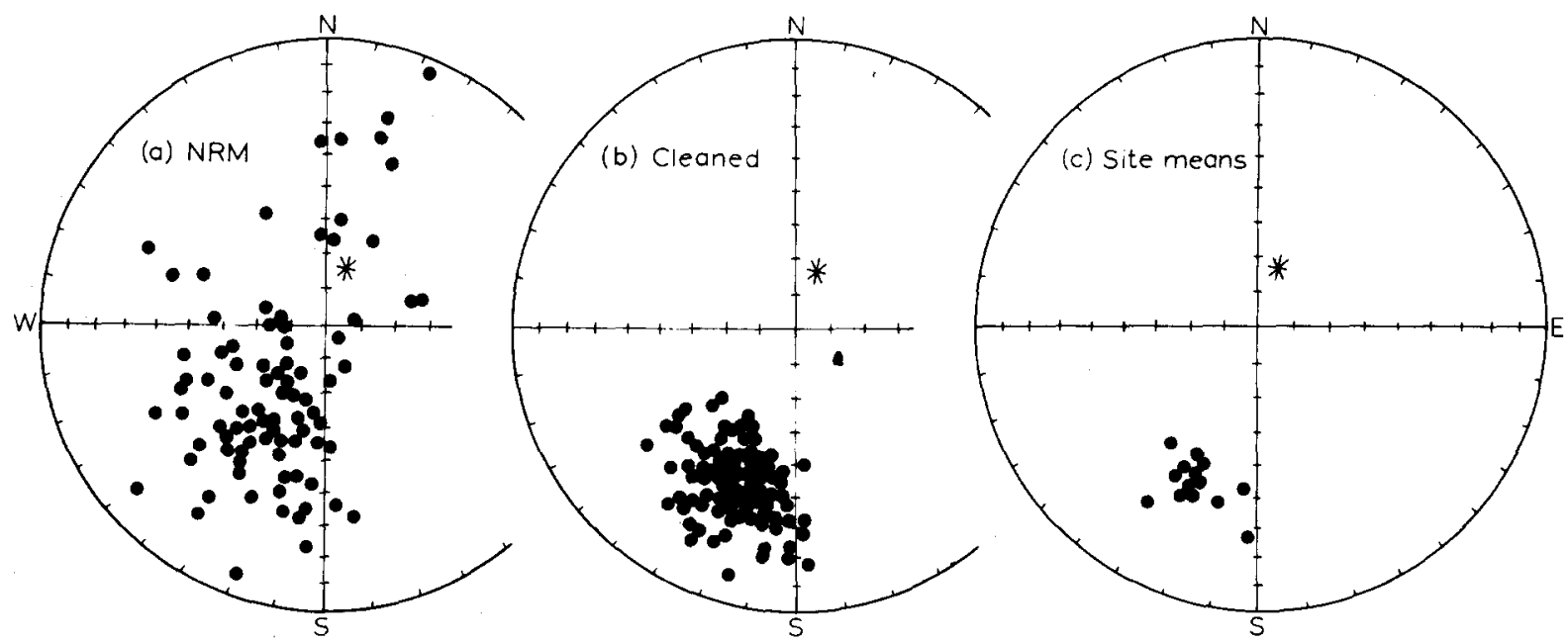

Fig. 5. Equal-area projections of the directions of magnetization of the Beltian Spokane Formation.

A. NRM's.

B. Characteristic directions of the samples.

C. Site mean directions. 
(a)

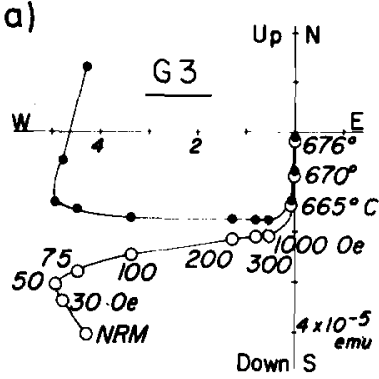

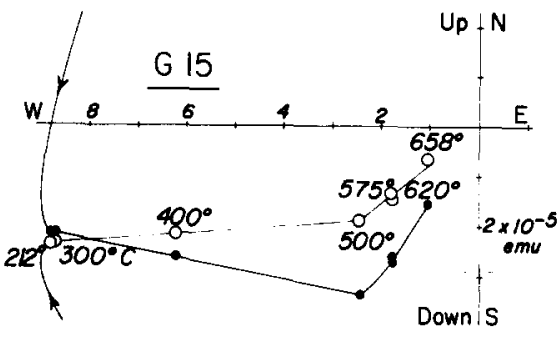

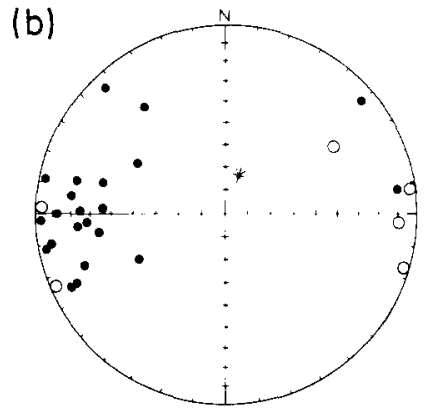

Fig. 6. A. Demagnetization diagrams of two samples of the Beltian Spokane Formation, showing intermediate directions of magnetization.

B. Equal-area projection of the directions of the intermediate magnetizations of the Spokane Formation.

any rate, when comparing the estimated temperatures of Eslinger and Savin (1973) with Dunlop and Buchan's theoretical graph for VpTRM acquisition (Fig. 1a), it appears that there is good agreement between observations and prediction: in Fig. $1 \mathrm{~b}$ the curve labeled "Beltian" indicates that the observed Eocambrian-Cambrian secondary magnetizations, which were generally removed in temperatures around $450-550^{\circ} \mathrm{C}$, could have originated through VpTRM acquisition at temperatures of about $300^{\circ} \mathrm{C}$ during approximately $1-10$ m.y.

\section{Secondary magnetizations in the Upper Keweenawan sediments}

In the two preceding sections we have described secondary magnetizations which may be dominantly of thermal origin (VpTRM's). It is well-known, however, that chemical secondary magnetizations are equally common in red beds and we include therefore some results describing their stability and origin.

Postdating extensive volcanic activity of ca. 1.1 b.y. B.P., a thick sequence of gray and red shales and sandstones was deposited in the Upper Peninsula of Michigan. We have studied the palaeomagnetism of two formations, the Nonesuch Shale and the Freda Sandstone (Henry et al., 1977) and we will briefly summarize the results. As in the case of the Beltian sediments, thermal demagnetizations revealed high-temperature characteristic directions which yielded a pole very similar to those of contemporaneous rock complexes in North America. Thermal demagnetization diagrams are shown in Fig. 7; the decay of the characteristic magnetizations is seen above temperatures of about $550^{\circ} \mathrm{C}$. Between temperatures of 200 and $550^{\circ} \mathrm{C}$ another, slightly different component of magnetization was sometimes eliminated in thermal as well as chemical demagnetization procedures (Fig. 7). The characteristic and intermediate directions of magnetization are shown in Fig. 8; though these directions are very similar and maybe not significantly different, they are clearly distinguished in the demagnetization diagrams such as those of Fig. 7. In view of the resulting pole
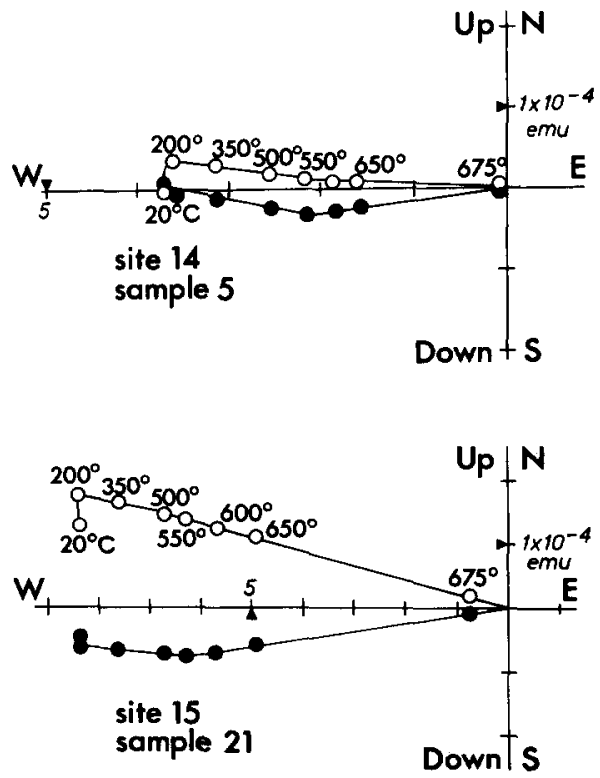

Fig. 7. Thermal demagnetization diagrams of samples from the Freda Sandstone. Note the two components of magnetization in these samples. 


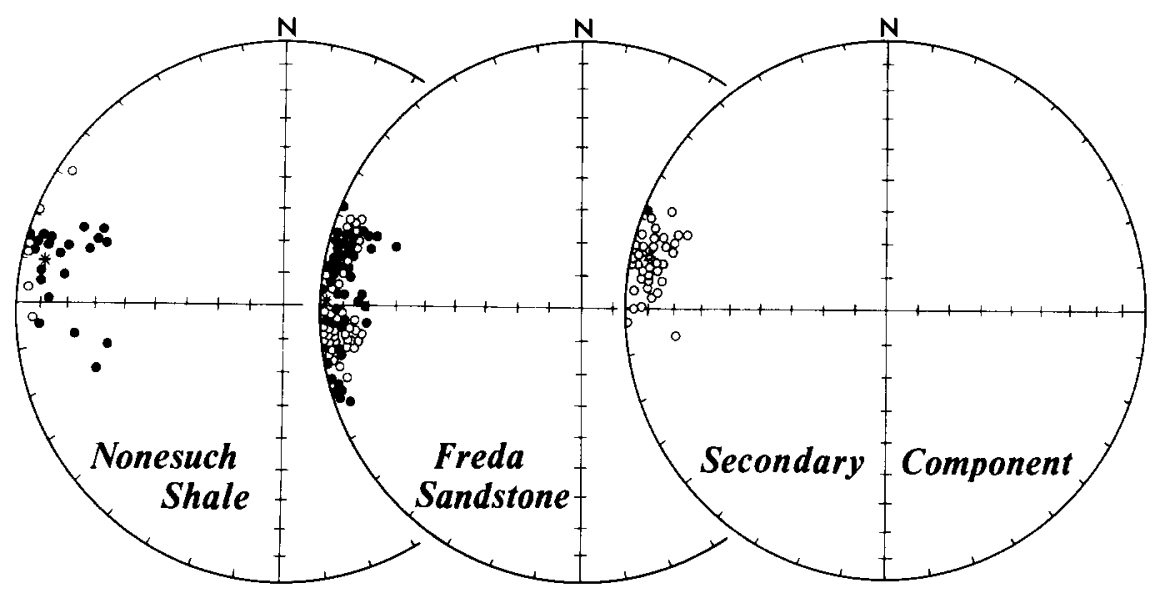

Fig. 8. Equal-area projection of the directions of the characteristic and secondary magnetizations in samples of the Freda Sandstone and the Nonesuch Shale (from Henry et al., 1977).

position of the intermediate component of magnetization, Henry et al. (1977) argued that this magnetization was younger (a secondary overprinting) and most likely of Late Precambrian age. This overprinting, however, cannot be of thermal origin. The sediments contain organic compounds and low-temperature minerals that would not have survived in-situ heating to more than about $100^{\circ} \mathrm{C}$ even for a short time (Barghoorn et al., 1965; Brown, 1971). Thus we attributed the secondary magnetizations to chemical causes, all the more likely since widespread $\mathrm{Cu}$ mineralization of these sediments is thought to be a chemical event as well (White, 1966; Brown, 1971), involving ionic exchange during fluid migration. This example illustrates that magnetic analysis alone cannot unambiguously distinguish VpTRM from a chemical remagnetization, since there is a striking similarity in stability, blocking-temperature range, and discreteness for the secondary magnetizations of both the Beltian and the Upper Keweenawan sediments.

\section{Discussion}

The three cases of secondary magnetizations described in the previous sections are causally and temporally reasonably well-defined. For further details of the palaeomagnetic analyses of these cases we refer to the original reports (Watts and Van der Voo, 1976; Vitorello and Van der Voo, 1977; Henry et al., 1977).
The pole positions calculated from all characteristic and secondary magnetizations mentioned above are plotted in Fig. 9, together with relevant segments of

- PRIMARY POLES

SECONDARY POLES

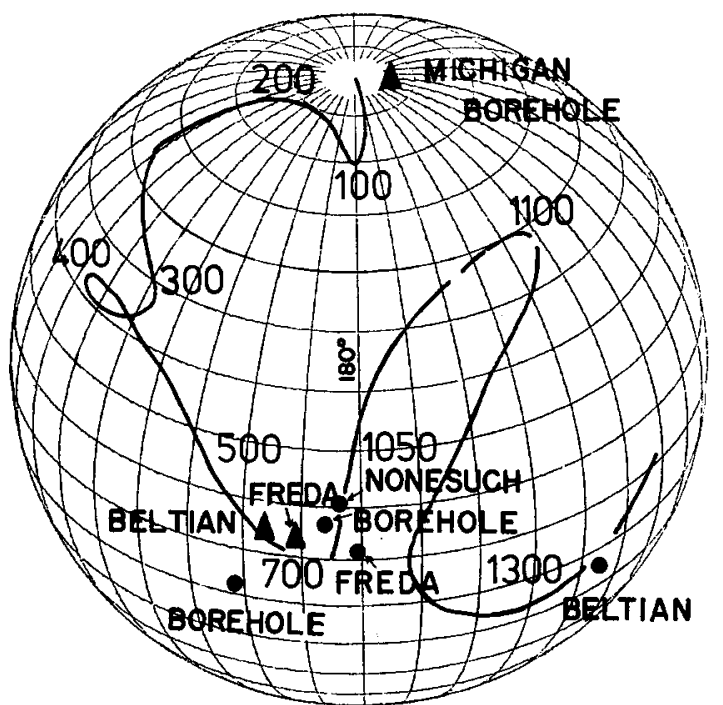

Fig. 9. Plot of all pole positions derived from the primary and secondary magnetizations mentioned in the text.

The apparent polar wander path for North America is indicated, excluding poles from those parts that possibly did not belong to North America (e.g., Grenville province, Newfoundland, coastal New Brunswick, coastal California and Oregon, Alaska). Ages are indicated in million years. 
the North American apparent polar wander path as currently conceived (Van der Voo and French, 1974; Irving and McGlynn, 1976). As stated earlier, the secondary magnetizations yield pole positions which fall on the apparent polar wander path, but in all cases on a relatively younger segment of the path than do those poles derived from the characteristic magnetizations. Comparisons between palaeomagnetic thermal stabilities and the palaeo- or present-day temperatures do not contradict Dunlop and Buchan's theoretical graphs of VpTRM acquisition, but we must caution against indiscriminate usage of the theoretical plots since chemical remagnetization could easily be mistaken for VpTRM. However, the theoretical relationships between observed blocking temperatures and palaeotemperatures may in some cases provide possibilities for determining palaeo-heat-flow values, provided that the sedimentary and erosional histories are sufficiently well known to enable an estimate of the depth of the samples at the time of VpTRM acquisition. One must recognize that a heat flow so determined may be representative of a transient state associated with the causative thermal event, and not the quasi-steady palaeo-heat-flow characteristic of the region before the thermal event.

\section{Acknowledgements}

We thank our colleagues, Drs. K.M. Storetvedt, D.T.A. Symons, N.D. Opdyke and D.V. Kent for their valuable comments on the manuscript. Support for the Michigan borehole project was obtained from Amoco, Shell Oil and McClure Oil Company, as well as from the National Science Foundation, grant EAR 76-02952; other aspects of this contribution were supported by grants GA-38038 and EAR 76-14996 (RVdV) and grant DES 75-17065 (HNP) from the National Science Foundation.

\section{References}

Barghoorn, S., Meinschein, W.G. and Schopf, J.W., 1965. Paleobiology of a Precambrian shale. Science, 148: 461-472.

Brown, A.C., 1971. Zoning in the White Pine Copper deposit, Ontonagon County, Michigan. Econ. Geol., 66: 543-573.

Buchan, K.L. and Dunlop, D.J., 1976. Paleomagnetism of the Haliburton intrusions: superimposed magnetizations, metamorphism, and tectonics in the Late Precambrian. J. Geophys. Res., 81: 2951-2967.
Eslinger, E.V. and Savin, S.M., 1973. Oxygen isotope geothermometry of the burial metamorphic rocks of the Precambrian Belt Supergroup, Glacier National Park, Montana. Bull. Geol. Soc. Am., 84: 2549-2560.

Goldich, S.S., Baadsgaard, H., Edwards, G. and Weaver, C.E., 1959. Investigations in radioactivity-dating of sediments. Bull. Am. Assoc. Pet. Geol., 43: 654-662.

Halls, H.C., 1976. A least-squares method to find a remanence direction from converging remagnetizations circles. Geophys. J.R. Astron. Soc., 45: 297-304.

Henry, S.G., Mauk, F.J. and Van der Voo, R., 1977. Paleomagnetism of the Upper Keweenawan sediments: the Freda Sandstone and the Nonesuch Shale. Can. J. Earth Sci., 14: 1128-1138.

Irving, E. and McGlynn, J.C., 1976. Proterozoic magnetic stratigraphy and the tectonic evolution of Laurentia. Philos. Trans. R. Soc. London, Ser. A, 280: 433-468.

Pullaiah, G., Irving, E., Buchan, K.L. and Dunlop, D.J., 1975. Magnetization changes caused by burial and uplift. Earth Planet. Sci. Lett., 28: 133-143.

Ross, C.P., 1959. Geology of Glacier National Park and the Flathead region, northwestern Montana. U.S. Geol. Surv., Prof. Pap. 296, 125 pp.

Roy, J.L. and Park, J.K., 1974. The magnetization process of certain red beds: vector analysis of chemical and thermal results. Can. J. Earth Sci., 11: 437-471.

Schmidt, V.A., 1976. The variation of blocking temperature in models of thermoremanence. EOS (Trans. Am. Geophys. Union), 57: 241 (abstract).

Stewart, J.H., 1972. Initial deposits in the Cordilleran geosyncline: evidence of a Late Precambrian ( $<850 \mathrm{MY}$ ) continental separation. Bull. Geol. Soc. Am., 83: 1345-1360.

Stupavsky, M. and Symons, D.T.A., 1976. Separation of magnetic components from AF step demagnetization data by least-squares computer models. EOS (Trans. Am. Geophys. Union) 57: 241 (abstract).

Van der Voo, R. and French, R.B., 1974. Apparent polar wandering for the Atlantic-bordering continents: Late Carboniferous to Eocene. Earth Sci. Rev., 10: 99-119.

Vitorello, I. and Van der Voo, R., 1977. Late Hadrynian and Helikian pole positions from the Spokane Formation, Montana. Can. J. Earth Sci., 14: 67-73.

Watts, D. and Van der Voo, R., 1976. Further paleomagnetic results from the Michigan basin deep borehole. EOS (Trans. Am. Geophys. Union) 57: 760 (abstract).

White, S.W., 1966. Sulfide-mineral zoning in the basal Nonesuch Shale, northern Michigan. Econ. Geol., 61: 11711190.

Williamson, P. and Robertson, W.A., 1976. Iterative method of isolating primary and secondary components of remanent magnetization illustrated by using the Upper Devonian Catombal Group of Australia. J. Geophys. Res., 81: 2531-2538.

Zijderveld, J.D.A., 1967. A.C. demagnetization of rocks: analysis of results. In: D.W. Collinson, K.M. Creer, and S.K. Runcorn (Editors), Methods in Palaeomagnetism, Elsevier, Amsterdam, pp. 254-286.

Zijderveld, J.D.A., 1975. Paleomagnetism of the Estérel rocks. Ph.D. Thesis, State University of Utrecht, Utrecht, 199 pp. 